\title{
1 Assessing the potential phytotoxicity of digestate from winery wastes
}

2 Cinzia Da Ros ${ }^{\mathrm{a}}$, Giovanni Libralatob, Annamaria Volpi Ghirardini ${ }^{\mathrm{a}}$, Marta Radaelli ${ }^{\mathrm{a}}$, Cristina 3 Cavinato ${ }^{\text {a* }}$.

$4{ }^{\mathrm{a}}$ Department of Environmental Sciences, Informatics and Statistics, University Ca' Foscari Venice, 5 Via Torino 155, 30172 Venezia-Mestre, Italy. (cinzia.daros@unive.it, voghi@unive.it, 6 marta.radaelli@unive.it, cavinato@unive.it).

$7 \quad{ }^{\mathrm{b}}$ Department of Biology, University of Naples Federico II, Complesso Universitario di Monte S. $8 \quad$ Angelo, Via Cinthia ed. 7, 80126 Naples, Italy. (giovanni.libralato@unina.it)

9

*Corresponding author: cavinato@unive.it, Department of Environmental Sciences, Informatics and Statistics, University Ca' Foscari Venice, Via Torino 155, 30172 Venezia-Mestre, Italy. 
2 In this study, digestate from winery wastes was investigated focusing on phytotoxicity using 3 macrophytes and evaluating the potential contribution of ammonium and copper. Spreading of 4 digestate on soil could represent a suitable approach to recycle nutrients and organic matter, creating an on site circular economy. In this study, digestate quality was evaluated considering both chemical-physical characteristics and biological toxicity applying germination test. The effluent did not meet the entire amendment quality standard defined by Italian law (Decree 75/2010 germination index $>60 \%$ with solution of $30 \% \mathrm{v} / \mathrm{v}$ of digestate), but bio-stimulation was observed at low doses (3.15-6.25\% v/v) for S. alba and S. saccharatum. The beneficial concentration agreed with Nitrate Directive dose and suggested that limited addition of digestate could have several positive effects on soil characteristics and on crop growth. Specific test using ammonium and copper solutions showed that these pollutants were not directly correlated to observed phytotoxicity.

\section{Keywords}

Anaerobic treatment; digestate; germination index; phytotoxicity; winery wastes ${ }^{1}$

Abbreviation: $\mathrm{AD}=$ anaerobic digestion; $\mathrm{AS}=$ Activated Sludge; $\mathrm{COD}=$ chemical oxygen demand; $\mathrm{CSTR}=$ continuous stirred tank reactor; D1 and D2= digestate samples 1 and 2; GAE=gallic acid equivalent; GI=germination index; HRT=hydraulic retention time; $\mathrm{OLR}=$ organic loading rate; $\mathrm{TS}=$ total solid; $\mathrm{VS}=$ volatile solids; $\mathrm{EC}=$ electrical conductivity; $\mathrm{pCOD}=$ particulate $\mathrm{COD}$; $\mathrm{sCOD}=$ soluble $\mathrm{COD} ; \mathrm{SRT}=$ sludge retention time; $\mathrm{TKN}=$ total Kiendhal nitrogen; $\mathrm{P}_{\text {tot }}=$ total phosphorus. 
2 Anaerobic digestion (AD) has been widely diffused in the last decades to treat several type of organic waste such as organic fraction of municipal waste [1], waste activated sludge [2], livestock effluents [3] and winery wastes [4]. The effluent of AD process is called digestate and its recovery can increase the economical and environmental process sustainability. The direct application of digestate to soil is currently considered an inexpensive option for its disposal and for recovery of their mineral and organic constituents for agricultural systems [5]. In fact, during the anaerobic process, part of organic nitrogen is transformed into ammonium, while phosphorus is partially converted in orthophosphate; both these chemicals are easily available for plants growth. Digestate application can consequently substitute or reduce the use of chemical fertilizer, though the amount must be calculated according with the Nitrate Directive (Directive 91/676/EEC). Considering the organic constituents, the labile fraction was mostly degraded during the AD process and lignin-like material, complex lipids and steroids became concentrated [6] reported that these compounds are humos precursors, consequently supply organic carbon in the soil. Moreover application of digestate leads to enhanced microbial processes such as nitrogen mineralization and ammonia oxidation [7,8], and enzymatic activity [9], which further increases the long-term nutrient release in soils [7,8]. Digestate improves soil physical properties [10] increasing water balance and soil structure [7]. In spite of digestate beneficial properties, it has to meet also quality standards in terms of heavy metals, polychlorinated byphenyls (PCBs), pathogens and phytotoxicity. Phytotoxicity is an interesting parameter evaluating the real digestate spreading impact on crops and it represents an index of its overall ecotoxicological impact. In fact the combined effect of the different contaminants mixed together, as well as their bioavailability, is difficult to estimate by chemical analysis while biological assays could supply the missing information [11]. Additionally, efforts should be made to identify the doses that will produce the desired fertilization effects ensuring the safety of agro-ecosystems [10].

To date, many countries introduced germination index (GI) to assess the quality of amendment as the result of the combination of macrophytes germination and root elongation. Generally it is an indicative limit value is provided in existing guidelines but only in Italy is a parameter enforced by law. The threshold for digestate acceptability as amendment according to the Italian legislation (D.Lgs $75 / 2010$ ) was set at GI $\geq 60 \%$ in a digestate samples diluted at $30 \%$.

GI was chosen for its simplicity, short time requirement (up to $72 \mathrm{~h}$ ) and sensitivity, being the germination phase strongly affected by environmental conditions [12]. It was applied mainly to compost [13-15] and recently to digestate [16,17]. Phytotoxicity test uses a matrix-based approach that considers the overall source of pollutants in the matrix and toxicants interaction. In most 
studies, it is applied as an indirect test, using an extract of the solid sample to identify its impact [11] and the results depend strongly on the solid-to-liquid ratio assumed. Instead direct test deals with the raw sample [18] and gives more realistic results, because all kind of interactions between contaminants, soil matrix and test organisms are included and all site specific effects are integrated.

The presence of so many complex chemicals in the digestate (e.g. including metal ions, macro and micro-nutrients, organic pollutants) caused ecotoxicological interactions varying from synergism to antagonism [19], making toxicity etiology difficult to identify [20]. Generally, phytotoxicity test carried out on digestate from livestock effluents showed stimulation at high dilution rate [5,17], while high concentrations showed germination inhibition. In contrast Gell et al. [21] did not observe any differences from the control using digestate deriving from cow manure, pig slurry and human excreta, and three plant species (Lactuca sativa L., Raphanus sativus L. and Triticum aestivum, L.). Germination index is usually inversely correlated with conductivity and ammonium concentration [5,20,22]. High ammonium concentration can reflect potential phytotoxicity [23-25], but a threshold limit is not well defined. Di Maria et al. (2014) reported that concentration of 16-25 g N$\mathrm{NH}_{4}^{+} / \mathrm{kgTS}$ inhibited seed germination in Lepidium sativum, while Tigini et al. [24] indicated that the inhibiting concentration was higher than $2000 \mathrm{mg} / \mathrm{L}$ of $\mathrm{N}_{-} \mathrm{NH}_{4}{ }^{+}$for Lepidium sativum and Cucumis sativum.

Salinity limits the germination of many plant species through osmotic effects or through ion toxicity [26]. It is reported by Boluda et al. (2011) [27] that salinity levels higher than 2.0-2.6 mS/cm can inhibit the number of Lactuca sativa germinated seeds and delay the germination process. Germination inhibition correlated by high conductivity level in the digestate was detected by several authors [5,17,24]. It can be associated with high concentration of sodium, chlorine, ammonium, and also metals. About metals in digestate, copper $(\mathrm{Cu})$ and zinc $(\mathrm{Zn})$ are the most recurrent $[5,14]$.

Phytotoxicity is not only correlated to chemical characteristics, but it depends on i) type of feedstock, ii) $\mathrm{AD}$ operational conditions [7,28] and iii) macrophyte species used during the experimental phase. Di Maria et al. [16] demonstrated that operational conditions could affect toxicity, in particular high organic loading rate (OLR) and short hydraulic retention time determined higher concentration of volatile fatty acids (VFAs), reducing the biological stability and, hence, the digestate germination index.

Considering the several parameters affecting digestate phytotoxicity, prediction of residual toxicity is difficult and experimental tests have to be carried out taking in consideration chemical characteristics and operational AD conditions. 
1 Winery wastes are interesting substrates for $\mathrm{AD}$ in wine producing countries because of their high biodegradability and pilot-scale experimentation showed that mesophilic process is the easiest to manage using hydraulic retention time higher than 20 days and organic loading rate of about $3 \mathrm{~kg}$ $\mathrm{COD} / \mathrm{m}^{3} \mathrm{~d}$ (chemical oxygen demand, COD) [29]. Digestate spreading on vineyards could represent a suitable approach to recycle nutrients and organic matter creating an on site circular economy, but the phytotoxicity evaluation has never been made.

In this study, digestate from winery wastes was investigated focusing on phytotoxicity with macrophytes looking for the potential contribution of ammonium and copper.

\section{Material and methods}

\subsection{Digestate production and sampling}

Two winery wastes, called D1 and D2, were considered: D1 was waste activated sludge (AS) from winery wastewater treatment and D2 was wine lees. They were collected in a cellar in Conegliano (Italy) producing about 30,000,000 L of wine per year. The $75 \%$ of sold wine is white one and most of it is producing by Charmat method along the whole year. Throughout the year it generates $1.6 \mathrm{~kg}$ of wine lees and $2.0 \mathrm{~L}$ of wastewater per L of wine. The wastewater has high COD concentration $(3,747 \mathrm{mg} / \mathrm{L}$ in average) and was treated inside the cellar borders by conventional activated sludge (AS) process. As reported by Da Ros et al. [4], the AS process operated with average hydraulic and sludge retention times (HRT and SRT) of $6.7 \mathrm{~d}$ and $35 \mathrm{~d}$, respectively. The oversized biological reactor volume allowed to operate with long HRT and SRT values, in order to withstand the load picks. The MLVSS was 3,010 mg/L and the corresponding food to microorganisms' ratio was 0.26 $\mathrm{kg} \mathrm{COD} / \mathrm{kg}$ MLVSS per day. The COD was completely removed (95\%) during the treatment and, in turn, $613 \mathrm{~kg}$ of dewatered waste AS was produced weekly. The substrate characteristics were reported in supplementary material and described in detail by Da Ros et al. (2016b).

A continuous stirred tank reactor (CSTR) with a working volume of $0.23 \mathrm{~m}^{3}$ was employed for anaerobic co-digestion of waste AS and wine lees. The temperature was maintained at $37{ }^{\circ} \mathrm{C}$ using an external jacket. PT100 probes (OMEGA Engineering Inc., Norwalk, CT, USA) monitored the temperature trend during process and managed the water recirculation pumps. The reactor operated with an organic loading rate of $3.2 \mathrm{~kg} /\left(\mathrm{m}^{3} \mathrm{~d}\right)$ of chemical oxygen demand (COD) and HRT of $23 \mathrm{~d}$. The organic load distribution between the two co-substrates considered the real waste flow characteristics: $80 \%$ of wine lees and $20 \%$ of waste AS.

The operational conditions were reached by a long start-up period (140 d) that consisted in slowing the increase of organic loading rates. The steady state was maintained for more than one year. Stability process parameters and biogas composition were analyzed twice per week. Nutrients 
1 content and COD concentration was measured once per week, while the phytotoxicity was evaluated twice in the whole period, eleven months far from each other.

\subsection{Analytical methods for digestate characterization}

\subsubsection{Physico-chemical analyses}

The substrates and the digester effluents were collected and monitored once a week to determine the total and volatile solid content (TS and VS), COD, total Kjeldahl nitrogen (TKN), and total phosphorus ( $\left.\mathrm{P}_{\text {tot }}\right)$ (American Public Health Association et al., 1999). The process stability parameters, $\mathrm{pH}$, total and partial alkalinity, and ammonia concentration were checked two or three times per week. At steady state conditions, the total polyphenols were analyzed spectrophotometrically using the Folin Ciocalteu assay [31]. The concentration was reported in terms of gallic acid equivalent per liter (mg GAE/L). Biogas was collected by a Tedlar ${ }^{\circledR}$ gas sampling bag and the biogas composition $\left(\mathrm{CO}_{2}, \mathrm{CH}_{4}, \mathrm{H}_{2}\right.$, and $\left.\mathrm{O}_{2}\right)$ was determined by a gas chromatograph (GC Agilent Technology $6890 \mathrm{~N}$ ) equipped with a column HP-PLOT MOLESIEVE, $30 \times 0.53 \mathrm{~mm}$ ID x $25 \mathrm{~mm}$ using a thermal conductivity detector and argon as gas carrier.

Dry milled digestate samples were analyzed to determine $\mathrm{Cu}$ and $\mathrm{Zn}$ content. Sample digestion was carried out using a microwave oven (Ethos 1-Milestone S.r.l Advance Microwave Digesting Labstation, Italy) in acid conditions (ultrapure hydrofluoric and nitric acids). Concentration of metals was determined by Inductively Coupled Plasma Mass Spectrometry (ICP-MS) equipped with a collision/reaction cell (ICP-ORS-MS) (Agilent 7500 ORS).

Cations $\left(\mathrm{Na}^{+}, \mathrm{K}^{+}, \mathrm{Mg}^{2+}\right.$ and $\left.\mathrm{Ca}^{2+}\right)$ were determined in the digestate samples after filtration on 0.45 $\mu \mathrm{m}$ membrane. Analyses were conducted using an ion chromatograph equipped with a conductivity detector (Metrohm model 761). A cation exchange column with carboxylic groups on polyvinyl alcohol material (model Metrosep C3-250) was used and the eluent was solution of $3 \mathrm{mM} \mathrm{HNO}_{3} / \mathrm{L}_{\text {. }}$

\subsubsection{Experimental design and phytotoxicity test}

Phytoxicity tests were carried out according to Beltrami [32] and OECD [33]. A battery of three macrophytes was selected including two dicotyledonous (Lepidium sativum and Sinapis alba) and one monocotyledon (Sorghum saccharatum) species [34]. Certified seeds were purchased from Ecotox Ltd. (L. sativum-lot LES290311; S. alba-lot SIA051011; S. saccharatum-lot SOS140611). Germination ( $\mathrm{G}, \%$ ), seedling elongation ( $\mathrm{SE}, \mathrm{mm})$, germination index (GI) expressed as percentage $\left(\mathrm{GI}=\left[100 \times(\mathrm{G} \times \mathrm{SE})_{\text {treatment }} /\left[(\mathrm{G} \times \mathrm{SE})_{\text {control }}\right]\right)\right.$ were considered as endpoints [35]. All endpoints were assessed in triplicate, otherwise explicitly indicated, including negative controls (ultrapure water). 
1 The threshold level for acceptability of negative controls was set at $10 \% \quad[33,35]$. The GI can assume values greater or lower than $100 \%$, where a value equal to $100 \%$ means that the seedling average length and germination rate between a specific treatment and the negative control are exactly the same [34]. If values are between $80 \%$ and $120 \%$, effects are likely the negative controls, otherwise values $>120 \%$ indicate biostimulation and $<80 \%$ inhibition effects [36]. Polystyrene Petri dishes equipped with a Whatman no. 1 filter were used as testing chambers containing $5 \mathrm{ml}$ of digestate, or a dilution of it with ultrapure water. Ten seeds were incubated per Petri dish for $72 \mathrm{~h}$ at $25{ }^{\circ} \mathrm{C}$ in the dark. Results were acquired using a digital camera corrected for objective distortion. The number of germinated seeds was registered and the whole length of seedling measured. Experimental design considered phytotoxicity characterization of two digestate samples (D1 and D2), and ammonium and copper synthetic solutions.

Both digestates were analyzed using different dilutions obtained by ultrapure water $(3.125,6.25$, $12.5,25,50$ and $100 \% \mathrm{v} / \mathrm{v}$ for D1, 5, 10, 25 and 50\% v/v for D2) and evaluating the overall toxicity of digestate via dilution-response relationship.

Several authors reported that ammonium is one of the most toxic compounds in the digestate, but they did not define its toxicity. In order to confirm literature data and estimate ammonium effect, phytotoxicity tests were carried out on $\left(\mathrm{NH}_{4}\right)_{2} \mathrm{SO}_{4}(10,100,500,1000$ and $10000 \mathrm{mg} \mathrm{N} / \mathrm{L})$ using the same battery of macrophytes.

The results of germination assays on digestate samples were thus elaborated considering ammonium content and, finally, the biological assay was repeated with D1 after partial ammonium stripping by air bubbling for $24 \mathrm{~h}$. The long bubbling simulated a post-treatment able to reduce ammonium concentration, remove volatile organic compounds and consequently increase the $\mathrm{pH}$; on the other hand this process did not modify the persistent compounds content such as heavy metals and salts. Neutral $\mathrm{pH}$ was corrected by diluted $\mathrm{HCl}$ addition and this dilution was considered to calculate real dilution $(2.9,5.8,11.5,23.1,46.1,92.2 \% \mathrm{v} / \mathrm{v})$ and ammonium concentration.

In order to evaluate the role of copper in seed germination, the results obtained with D1 exposure was analyzed considering $\mathrm{Cu}$ content and compared with response using solution of copper sulfate $\left(\mathrm{CuSO}_{4}\right)$ with concentration ranging from $1 \mathrm{mg} \mathrm{Cu} / 1$ to $1000 \mathrm{mg} \mathrm{Cu} / 1$.

\subsection{Data analysis}

Root elongation was carried out with ImageJ [37]. Whenever possible, toxicity was expressed as effective median concentration generating a $50 \%$ in the treated population (EC50). Otherwise, toxicity was expressed as percentage of effect at its relative exposure concentration. The significance of differences between average effect values of different experimental treatments and controls was assessed by the analysis of variance (ANOVA) considering a significance threshold 
1 level always set at 5\%. When ANOVA revealed significant differences among treatments, post-hoc tests were carried out with Dunnett's method and Tukey's test. Statistical analyses were performed using Microsoft Excel 2013/XLSTATC-Pro (Version 7.2, 2003, Addinsoft, Inc., Brooklyn, NY, USA).

Two parametric models were used to calculate EC50 and presence of stimulation effects. As suggested by Vanewijk and Hoekstra (1993), logistic model was used when concentration-response toxicity data followed a sigmoidal curve, while linear logistic model (Brain and Cousens, 1989) was applied when a stimulation for low concentrations (hormesis) of otherwise toxic compounds was detected. The logistic (Eq. 1) and linear-logistic (Eq. 2) models were used to describe experimental data.
$y=\frac{k}{1+\left(x / x_{0}\right)^{b}}$
Eq. 1
$y=\frac{k(1+f x)}{1+\left(2 f x_{0}+1\right) *\left(x / x_{0}\right)^{b}}$
Eq. 2

Where $y$ is the effect expressed as GI, $x$ the digestate concentration in terms of percentage over total solution volume and $k$ stands for the $\mathrm{y}$ value at $\mathrm{x}=0$. The parameter $b$ relates to the slope of the tangential line in the point of inflection on response-dose curve or stands for the slope of the line on logit-log-scale. $x_{0}$ is the EC50 value and $f$ stands for hormesis, when it has positive value the curve shows an increase of response value at low concentrations.

A nonlinear least-square regression analysis was performed using Excel ${ }^{\mathrm{TM}}$ to determine the two models equations parameters $\left(k, x_{0}, b\right.$ and $\left.f\right)$ and the EC50 defined by $x_{0}$ value. The correlation coefficient $\left(\mathrm{R}^{2}\right)$ was calculated to assess the goodness-of-fit of each model, like as the significance of stimulation. When the equation model is known, the effect for each dilution could be calculated.

\section{Results and discussion}

\subsection{Chemical-Physical characteristics of digestate}

Two digestate samples (D1 and D2) were collected from pilot-scale reactor eleven months far between each other. No dewatering was carried out consequently the samples had low dry matter content (22.4 and $22.7 \mathrm{gTS} / \mathrm{kg})$. They can be classified as liquid substrate because dry matter was lower than $15 \%$ and can be evaluated without operating an extraction. Digestate samples were characterized both by $\mathrm{pH}$ values > 7; D2 had a more alkaline value ( $\mathrm{pH} 7.70$ vs D1 pH 7.35) because of the greater ammonium concentration $(639 \mathrm{mgN} / \mathrm{lvs} \mathrm{D} 1$ with $321 \mathrm{mgN} / \mathrm{l})$. Also buffer capacity could affect $\mathrm{pH}$, but in this case partial and total alkalinity (PA and TA) can be considered comparable (D1 TA 2,121 $\mathrm{mgCaCO}_{3} / 1$, D2 TA 2,331 $\mathrm{mgCaCO}_{3} / \mathrm{l}$ ). The highest conductivity was 
observed in the second sample D2 $(5.74 \mathrm{mS} / \mathrm{cm})$, probably due to higher ions concentration such as potassium ion $(591 \mathrm{mg} / \mathrm{l})$ and ammonium concentration. Both digestates had EC values considered able to inhibit seed germination [27].

The organic matter content, expressed as COD, was comparable in D1 and D2 (696 and $687 \mathrm{mg}$ $\mathrm{COD} / \mathrm{g} \mathrm{TS}$, in that order) and similar to other digestates from different origin [24]. Regarding the plant nutrient content and hence the fertilizer value, total nitrogen content (sum of ammonium and TKN content on dry matter) was 1.4 and $1.7 \mathrm{gN} / \mathrm{L}$ in D1 and D2, respectively. The difference was mainly due to the ammonium content that was $23 \%$ and $37 \%$ of the total nitrogen. Hence, this nutrient is mainly in the organic form (76 and $63 \%$ of total nitrogen), less available for the plant and slowly released to the environment. Total and volatile solids content and particulate COD, TKN and $\mathrm{P}_{\text {tot }}$ were comparable, because they are correlated with operational conditions applied (i.e. organic loading rate, HRT and temperature) and affected by waste AS.

The characteristics associated with liquid fraction (i.e. $\mathrm{pH}$, alkalinity, conductivity, soluble COD and ammonium nitrogen) were different. The differences were due to wine lees that had a great variability range. The soluble COD (sCOD) was slightly higher in the second sample, but both D1 and D2 had VFAs $<1,500 \mathrm{mg} / 1$, which is the proposed threshold limit for digestate fertilizer use within the end-of-waste criteria [39]. Presence of polyphenols $<50 \mathrm{mgGAE} / \mathrm{L}$ was characteristic of digestate from winery waste [4]. The polyphenolic compounds could inhibit or delay the germination, anyway they are degraded in aerobic conditions and could serve as precursor for the formation of humic acids in soil [40]. Copper is used in the vineyard for plant health and during the winemaking process. In the digestate $\mathrm{Cu}$ concentration was around $431 \mathrm{mg} / \mathrm{kg}$ TS and derived from wine lees (Da Ros et al., 2014). The digestate did not meet the threshold limit for fertilizer in Italy (230 mgCu/kgTS, D.Lgs 75/2010) and proposed end-of-waste criteria from $3^{\text {rd }}$ Working Document (100 mg Cu/kgTS, Saveyn and Eder, 2014). Digestate samples complete characterization is reported in supplementary material.

\subsection{Digestate phytotoxicity}

\subsubsection{Phytotoxicity of D1}

The number of germinated seeds of L. sativum was reduced from $93 \%$ in the control test to about $80 \%$ when digestate solutions at 3.125, 6.25 and $12.5 \%$ were used. Negative controls $(<10 \%)$ were acceptable for all testing species according to Libralato et al. [42]. Less diluted samples significantly decreased the number of germinated seeds. 
1 Seedling elongation increased when $3.125 \%$ of D1 was applied $(+35 \%)$ and dilutions of 6.25 and ( 2 3 .

$12.5 \%$ had no effect on elongation after normalization to the negative control. Higher D1 concentrations inhibited root development and seedling development. GI showed a slight stimulation at the lowest D1 concentration $(3.125 \% \mathrm{v} / \mathrm{v})$. ANOVA evidenced no significant differences after the exposure from $0 \%$ to $12.5 \%(\mathrm{p}<0.05)$, while inhibition was detected for higher concentrations $(25,50$ and $100 \% \mathrm{v} / \mathrm{v})$.

S. alba was less sensitive than L. sativum in terms of germinated seeds, in fact the germination rate was about $90 \%$ up to $25 \%$ of the digestate. The most interesting effect of digestate was observed on seed elongation: root length increased from $29.3 \mathrm{~mm}$ up to $50 \mathrm{~mm}$ with D1 dilutions of 3.125, 6.25 and $12.5 \%$. The difference between the control and treatments was not relevant up to $25 \%$ of D1. Higher concentrations $(25,50$ and $100 \% \mathrm{v} / \mathrm{v})$ inhibited both seed germination and elongation. GI agreed with these observations: important stimulation (74-78\%) was observed at lower digestate concentration (3.125 and $6.25 \% \mathrm{v} / \mathrm{v})$, the effect was not significant at $25 \%$ of D1, while germination was completely inhibited at 50 and $100 \%$ of digestate.

The number of $S$. saccharatum germinated seed was not significantly different considering 3.125\%$25 \%$ D1 treatments $(\mathrm{p}<0.05)$, while greater dilutions inhibited germination. Germination was observed also with raw D1 while the other species did not germinated at the same conditions $(\mathrm{RE}<1$ $\mathrm{mm}$ ), then $S$. saccharatum appeared more tolerant to raw digestate. Elongation stimulation was detected with $3.125 \%$ of D1, while gradual inhibition was observed for increasing D1 concentrations. GI showed stimulation (up to $51 \%$ at $3.125 \% \mathrm{v} / \mathrm{v}$ of D1), while lower dilution rates $(>6.25 \% \mathrm{v} / \mathrm{v})$ had inhibiting effect.

Dilution-response relationships were analyzed using two models (logistic and linear-logistic) in order to evaluate which model fitted better the experimental data according to the absence or presence of biostimulation event (Figure 1). The linear-logistic fitted best except for L. sativum. The fitting of logistic model with the L. sativum data $\left(\mathrm{R}^{2} 0.98\right)$ confirmed the absence of biostimulation with an EC50 value of $20 \%$ of D1. Linear-logistic model fitted with $S$. alba $\left(\mathrm{R}^{2} 0.98\right)$ and $S$. saccharatum $\left(\mathrm{R}^{2}\right.$ 0.95). The EC50 values calculated on this model basis were $30 \%$ and $19 \%$ for $S$. alba and $S$. saccharatum, respectively. 


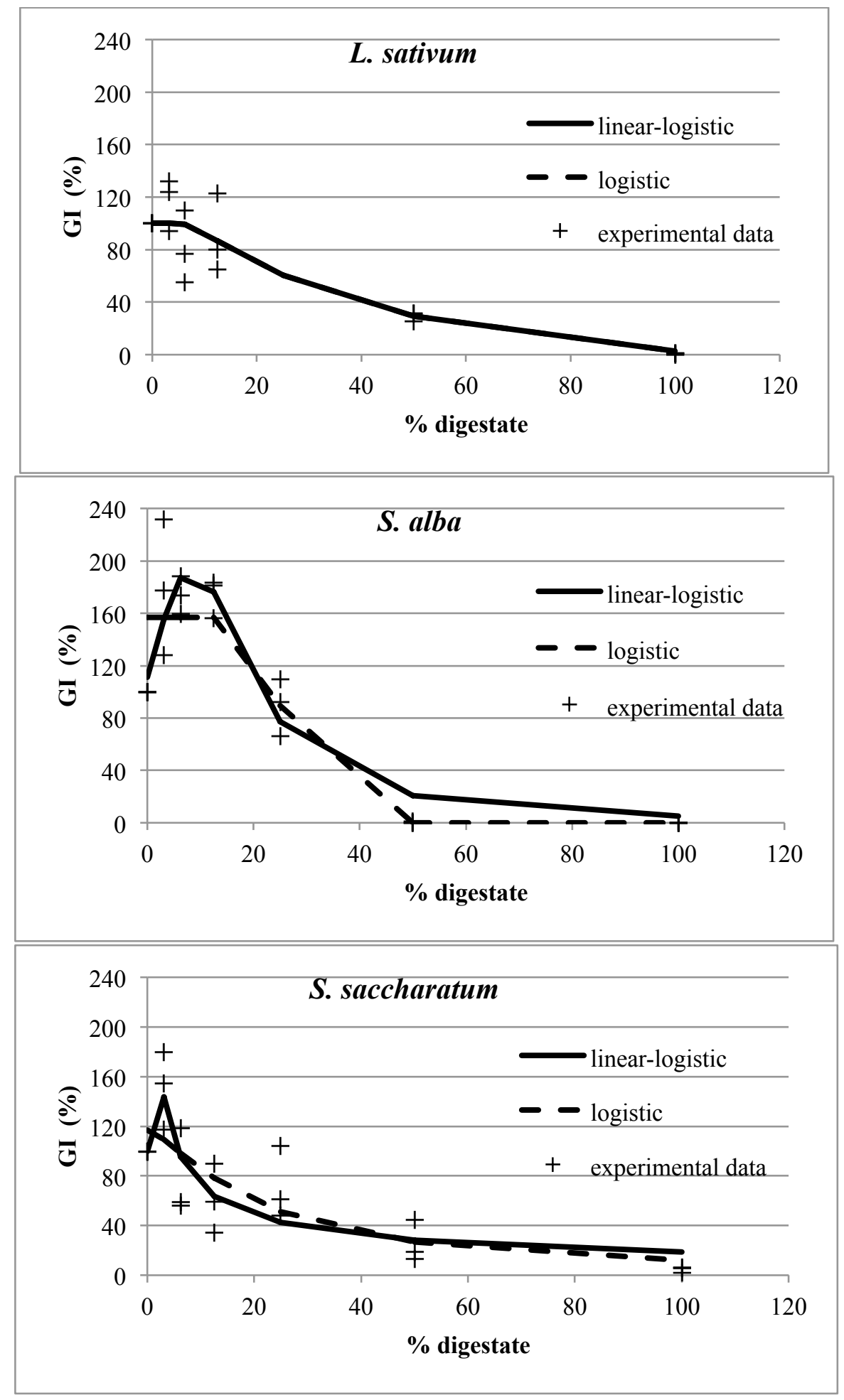

4 Figure 1. Germination index values determined using D1, trend predicted by logistic and linear-logistic 5 models 


\subsubsection{Phytotoxicity of D2}

D2 inhibited the germination also at lowest concentration; in fact at dilution of $5 \% \mathrm{v} / \mathrm{v}$ germinated seeds are the $67 \%$ of total seeds. The difference between dilutions of $5 \%$ and $10 \% \mathrm{v} / \mathrm{v}$ is not significant, while at higher digestate concentration (25 and $50 \% \mathrm{v} / \mathrm{v}$ ) only $10-13 \%$ of seeds germinated. RE was similar in the control and in the test carried out with digestate most diluted (5\%), latter it gradually reduced increasing digestate dose. GI gradually reduced increasing the digestate content in the tested solution. The analysis of variance indicated that results with digestate at $5 \%$ and $10 \%$ were statistically similar $(\mathrm{p}<0.05)$. Hence, the toxicity was significant for D2 dilution $>10 \%$ and appeared comparable at $25 \%$ and $50 \%$ of D2.

The percentage of $S$. alba germinated seed was comparable with the control test up to $25 \%$ of D2, while a significant inhibition on root elongation was observed at lower concentration (up to -78\%). This indicated that the substrate affect more the root development than germination. Higher concentrations $(>25 \%)$ significantly reduced both seed germination and root elongation. Statistical analysis clustered GI results in two groups: i) $<10 \%$ of D2: treatments had no effect on plant development; ii) $>10 \%$ of D2: significant phytotoxicity including both germination inhibition and/or root elongation inhibition. Total inhibition was observed when digestate was diluted two times.

The lower sensitivity of $S$. saccharatum was confirmed also in the case of D2. The percentage of germinated seed was reduced from approximately $80 \%(5-10-25 \%$ of D2) to $67 \%$ at $50 \%$ of D2. The root elongation reduced by $23 \%$ considering a $10 \%$ of $\mathrm{D} 2$, with inhibition increasing at higher D2 concentrations. The effect at $25 \%$ and $50 \%$ of D2 were not significantly different. The average GI values indicated that toxicity was inversely correlated to digestate content. Standard deviations observed on results using concentration form $10 \%$ and $25 \% \mathrm{v} / \mathrm{v}$ were higher than $30 \%$ and indicated a wide response variability of this macrophyte to digestate. Moreover no significant differences $(\mathrm{p}<0.05)$ between the highest evaluated doses $(25 \%$ and $50 \% \mathrm{v} / \mathrm{v})$ were evidenced.

D2 data fitted better with the logistic model $\left(\mathrm{R}^{2} 0.996\right.$ for L. sativum and S. alba, $\mathrm{R}^{2} 0.95$ for $S$. saccharatum), because no hormesis was detected. EC50 values determined were $10 \%, 23 \%$ and $18 \%$ of D2 for L. sativum, S. alba and S. saccharatum, respectively (Figure 2). 

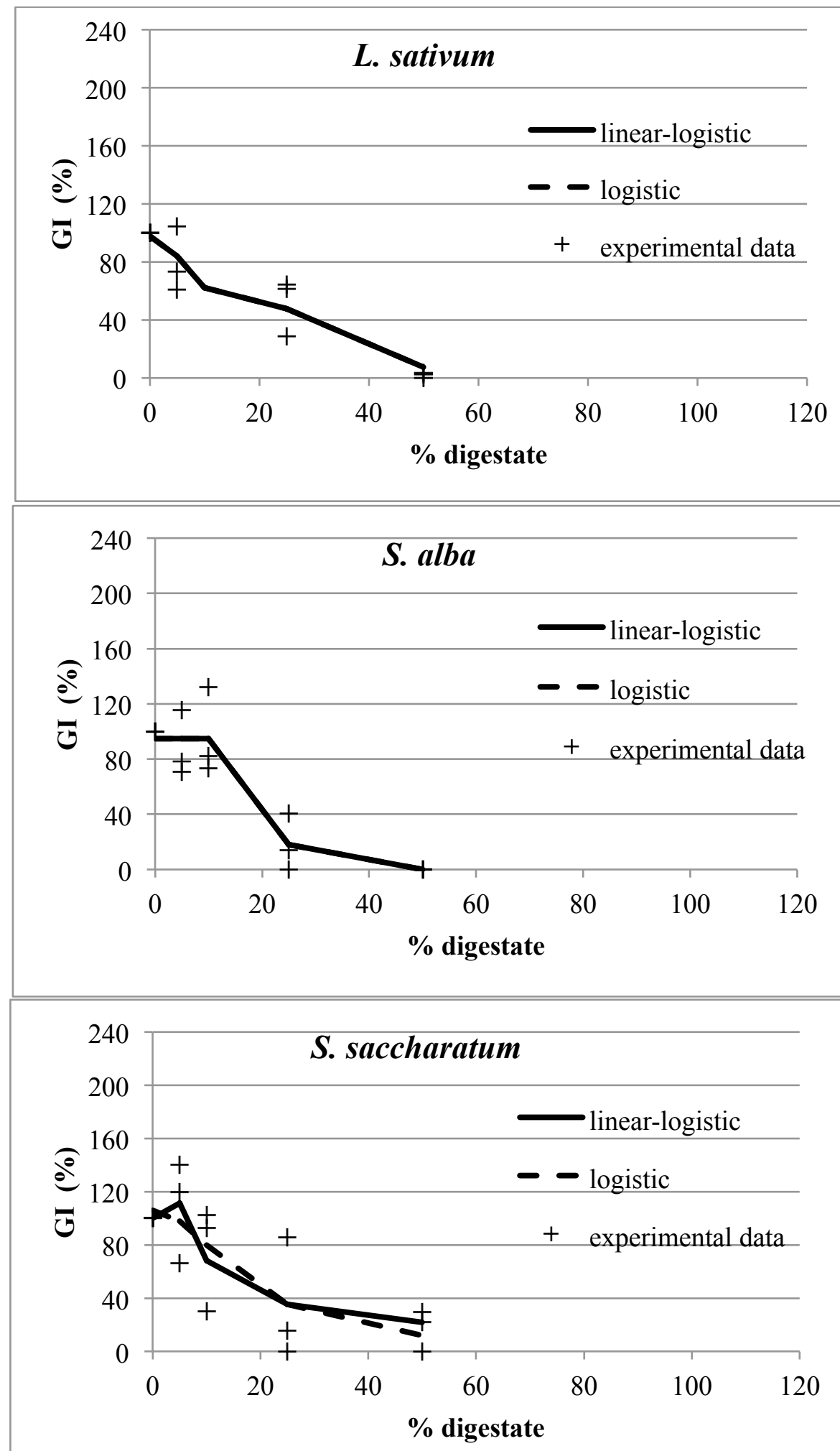

3

4 Figure 2 Germination index values determined using D2, trend predicted by logistic and linear-logistic 5 models 


\subsubsection{Comparison of D1 and D2}

In all the tests the toxicity is related to digestate concentration. Low doses $(3.125 \% \mathrm{v} / \mathrm{v}$ of D1 and $5 \% \mathrm{v} / \mathrm{v}$ of D2) caused GI comparable to controls, germination reduced increasing digestate content until to totally inhibit the germination at $50 \% \mathrm{v} / \mathrm{v}$ of digestate. S. saccharatum is the less sensitive species because germination was observed also with $50 \% \mathrm{v} / \mathrm{v}$ of digestate concentration (GI of $25 \%$ and 30\% using D1 and D2, respectively).

D1 and D2 were collected from the anaerobic reactor working at the same operational conditions (e.g. temperature, HRT, OLR, substrate types) at a time-distance of eleven months. Inconstancy on wine lees characteristics affected the final digestate parameters, despite that long HRT (23 d) moderated the effluent variability. The differences observed in terms of $\mathrm{pH}$, conductivity, ammonium concentration and soluble COD, were due to wine lees fed to the reactor and had consequence on the digestate quality and its phytotoxicity.

As consequence of different digestates characteristics, also phyto-toxicity changed using D1 and D2. Significant stimulation at low doses $(3.125-5 \% \mathrm{v} / \mathrm{v})$ was observed on $S$. alba and $S$. saccharatum when D1 was applied, while hormesis was not detected in D2. The EC50 values (Table 1) confirmed the higher toxicity of D2 exception for $S$. saccharatum. Germination inhibition of $50 \%$ of $L$. sativum was detected with $20 \% \mathrm{v} / \mathrm{v}$ of D1 and $10 \% \mathrm{v} / \mathrm{v}$ of D2, while EC 50 values are less different for S. alba (30\% v/v for D1 and 23\% v/v of D2).

Table 1 EC50 values along with 95\% confidence for D1 and D2 using L. sativum, S. alba and S.saccharatum. The values were estimated using the model (logistic or linear-logistic) that better fits experimental behaviour.

\begin{tabular}{lll}
\hline & $\mathrm{D} 1$ & $\mathrm{D} 2$ \\
\hline L. sativum & $20 \% \pm 7 \%$ & $10 \% \pm 3 \%$ \\
S. alba & $30 \% \pm 4 \%$ & $23 \% \pm 6 \%$ \\
S. saccharatum & $19 \% \pm 13 \%$ & $18 \% \pm 16 \%$ \\
\hline
\end{tabular}

S. saccharatum appeared less sensitive to digestate variability and more tolerant to high concentrations, in fact the complete inhibitions was observed only using the raw digestate (D1) while solution with $50 \% \mathrm{v} / \mathrm{v}$ of digestate inhibited germination for $70 \%$ and $75 \%$ for D1 and D2, respectively. On the other hand it appear the most variable macrophyte in fact the standard deviation values were often around the $30 \%$.

Germination tests results agreed with inhibiting effect of increasing concentration of ammonium and salinity level reported by studies on AD effluents [16,17,24,43]. Despite the relationship found 
1 by Di Maria et al. (2014), the inhibitions of germination were not related to presence of readily biodegradable COD: in fact sCOD values were not relevant in the digestates $(<400 \mathrm{mg} / \mathrm{L})$. While the presence of metals, mainly $\mathrm{Cu}$, should be taken into consideration because its concentration was higher than law limits $(230 \mathrm{mgCu} / \mathrm{kg}$ TS $)$ even if it is difficult to estimate their bioavailability and bioaccessibility in digestate.

The toxicity effect of solution containing 30\% of both D1 and D2, as requested by Decree 75/2010, had a GI $<60 \%$ on L. sativum, meaning that an excess toxicity could be present for crops [16]. In order to reach the GI of $60 \%$ the applied dilution should be $18 \% \mathrm{v} / \mathrm{v}$ of D1 and $8 \% \mathrm{v} / \mathrm{v}$ of D2.

Nitrate Directive should be taken in consideration in addition to Decree 75/2010, because it defined the nitrogen fertilization in order to protect groundwater from nutrients' pollution and avoid eutrophication. The maximum rate of nitrogen allowed by Directive on Nitrate Vulnerable Zones, such as Po Valley, is 170/kg N/hectare year. Considering this limit and that the soil depth interested by fertilization is equal to $30 \mathrm{~cm}$, the amount of D1 and D2 used per hectare would be respectively 124 and $98 \mathrm{~m}^{3}$, corresponding to $4.1-3.3 \%$ of dilution. In this concentration range no significant inhibition was detected, moreover stimulation could be sometimes observed.

Comparing the dilution obtained on Nitrate Directive basis $(3.3-4.1 \% \mathrm{v} / \mathrm{v})$ with that defined by Decree $75 / 2010$ for germination test $(30 \% \mathrm{v} / \mathrm{v})$, the GI limit appeared strongly preventive for digestate case and does not consider nitrogen amount. Considering the end-of-waste approach recently suggested at European level [39], a revision of threshold limit for digestate should be taken into account.

\subsection{Ammonium phytotoxicity}

Ammonium solutions (10, 100, 500, 1000 and $10000 \mathrm{mg} \mathrm{N} / \mathrm{L})$ were analyzed by germination tests in order to evaluate the effect of this sole compound.

L. sativum germinated seeds percentage was higher than $90 \%$ in all conditions, RE and GI followed the logistic model trend (Figure 3). EC50 for this species is $514 \mathrm{mg} \mathrm{N} / \mathrm{l}$, that is a concentration higher than in D1.

Concentration of $10,000 \mathrm{mg} \mathrm{N} / \mathrm{L}$ completely inhibited $S$. alba germination, while percentage of germinated seeds was higher than $80 \%$ at lower concentrations. In terms of RE, $100 \mathrm{mgN} / 1$ slightly stimulated root development (11\%). Although the stimulation at $100 \mathrm{mg} \mathrm{N} / \mathrm{L}$ is not significant compared to negative controls, the overall trend was better described by linear-logistic model and the corresponding EC50 was $490 \mathrm{mg} \mathrm{N} / 1$. 

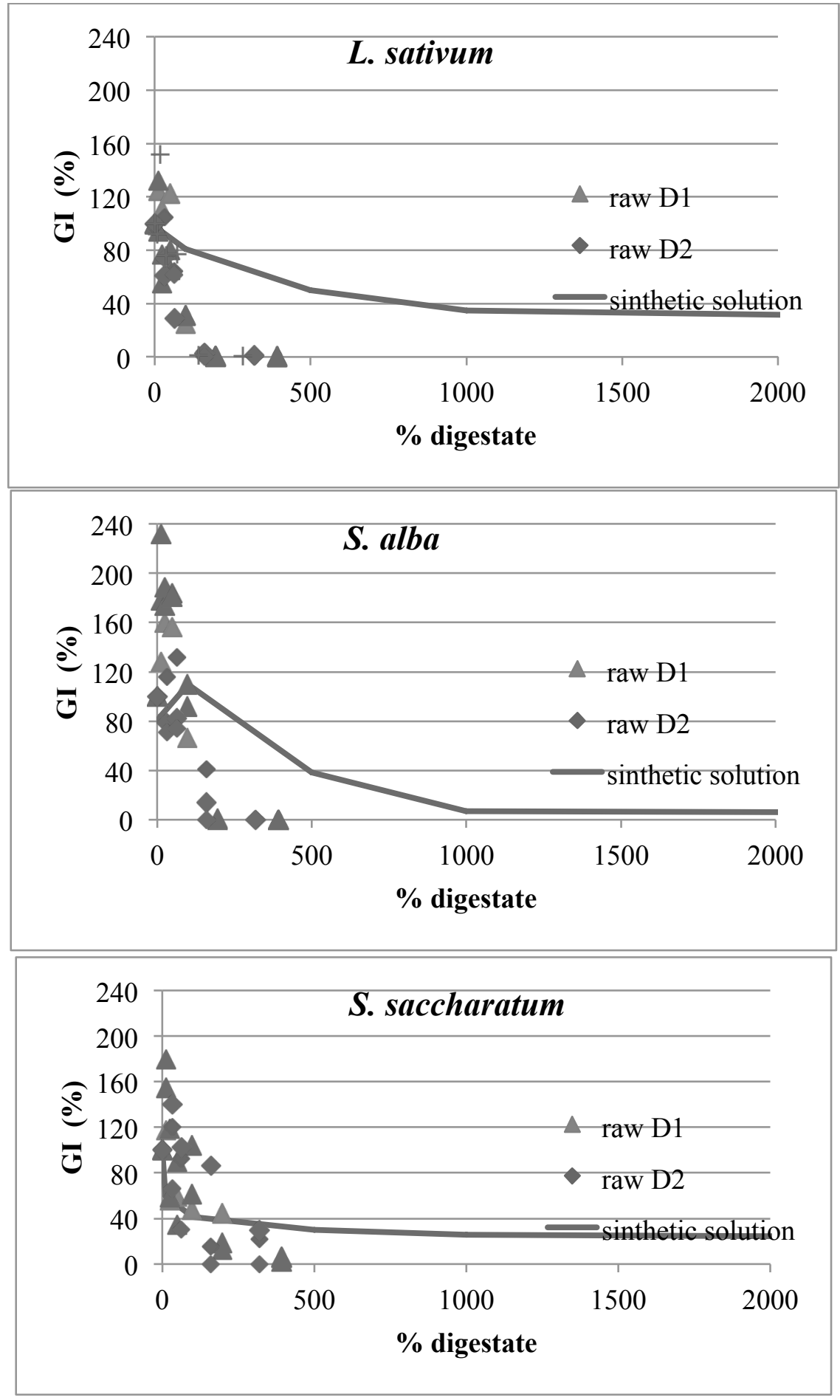

$4 \quad$ Figure 3 Effect of D1, D2 and synthetic solution of ammonium sulfate

5 S. saccharatum seeds germinated up to $1,000 \mathrm{mg} \mathrm{N} / \mathrm{L}$, while were completely inhibited at highest 6 concentrations. RE and GI decreased according to ammonium concentration and evidenced higher 7 sensitivity to ammonium than other seeds. In fact, also the lowest concentration (1 $\mathrm{mg} \mathrm{N} / \mathrm{L})$ 8 inhibited seed elongation up to $48 \%$, while inhibition was $6 \%$ and $38 \%$ for L. sativum and S. alba. 9 Logistic model indicated that the EC50 was $37 \mathrm{mg} \mathrm{N} / \mathrm{L}$ : the concentration was one order of magnitude lower than value estimated using the other species. 
1 Toxicity data showed that ammonium could not be considered as the main toxicant inhibiting seed germination because result obtained with digestate and synthetic solution did not agree. L. sativum and $S$. alba appeared the two species most sensitive to ammonium, with an EC50 of approximately $500 \mathrm{mg}$ N/1. This value alone did not explain the whole inhibition using digestates diluted two times and corresponding to 197 and $320 \mathrm{mg} \mathrm{N} / 1$, using D1 and D2, respectively.

Figure 3 confirmed that concentration-response curves had different trend using the digestate and the synthetic solutions. In particular using ammonium solution the hormesis was not detected at low concentration and inhibition to L. sativum and S. alba was higher than that observed with D1 and D2, except for $S$. saccharatum. EC50 values of $S$. saccharatum were quite similar (37 mg N/1 for synthetic solution, $59 \mathrm{mg} \mathrm{N} / 1$ for D1 and $121 \mathrm{mg} \mathrm{N} / 1$ for D2) but total inhibition using the digestate was observed at concentration lower than $500 \mathrm{mg} / \mathrm{L}$ while with synthetic solution limited germination was also observed at highest concentration $(10,000 \mathrm{mg} \mathrm{N} / \mathrm{L})$. Other toxicants in digestate inhibited germination or a synergistic effect could increase ammonium toxicity.

Since the analysis of synthetic solution is interesting but reductive compared to the complexity of digestate, the authors tried to strip ammonium out of the digestate D1 via an overnight aeration. Ammonium concentration reduced from 393 to $307 \mathrm{mg} \mathrm{N} / 1$ using this treatment while salinity and heavy metals content could be considered constant. On the other hand, during aeration more chemical-physical reaction occurred, like the oxidation of reduced compounds (e.g. hydrogen sulfide, organic compounds) and their sub-sequent volatilization. The concentration-response trend using aerated sample changed on basis of macrophyte species.

L. sativum inhibition reduced according with ammonium concentration in fact the EC50 was constant in the tests carried out with raw and aerated D1 (79 $\mathrm{mg} \mathrm{N} / 1)$, while treated digestate concentration-response curve showed stimulation at low concentrations. Probably, the removal/oxidation of other toxicants reduced phytotoxicity for this species.

The toxicity of $S$. alba was not related to ammonium concentration (Figure 4) but to pollutants that were not lost during the stripping. In fact the EC50 values were comparable in term of digestate dilution (30\% v/v for both D1 samples) but different on ammonium concentration basis (118 and 92 $\mathrm{mg} \mathrm{N} / \mathrm{L}$ for raw and aerated D1, respectively).

The concentration-response curve of $S$. saccharatum changed: D1 showed biostimulation at low concentration and hormesis was detected, while aerated D1 is better described by logistic model. As consequence the EC50 in test with aerated D1 was lower 13\% v/v and $40 \mathrm{mg} \mathrm{N} / \mathrm{L}$ (versus 19\% v/v and $75 \mathrm{mgN} / \mathrm{L}$ using raw D1). Phytotoxicity to $S$. saccharatum slightly increased by short period of aeration as reported by Vallini et al. [44] probably because the macrophyte was more sensitive to oxidized compounds, generated during the aerobic process. 

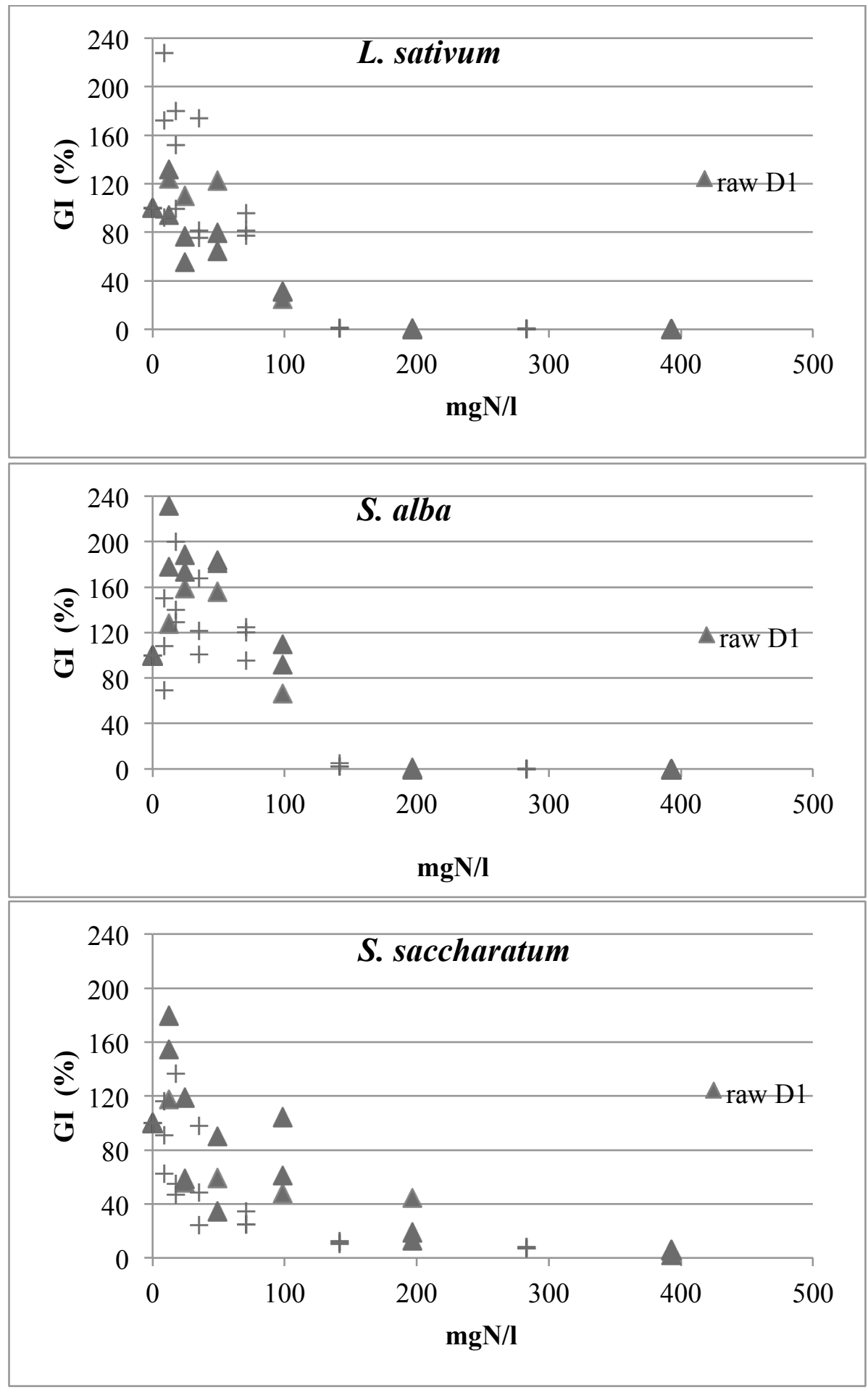

$4 \quad$ Figure 4 Effect of raw and aerated D1

\section{$5 \quad 3.4 \quad$ Copper phytotoxicity}

6 Metals are considered toxic for microorganisms, plants and animals, but it is difficult to estimate the

7 amount of bioavailable metals, because some of them are borderline between micro-nutrients and 8 toxicity. By date, legislation defined threshold limits expressed as total metal content on dry matter 9 basis but the toxicity should consider chemical forms and behavior in environment. The most 
1 hazardous form is soluble one such as copper ion $\left(\mathrm{Cu}^{2+}\right)$, then phytotoxicity of $\mathrm{Cu}^{2+}$ was analyzed

2 by the synthetic solution and the results were compared with those from digestates exposure.

3 The dose-response curves with synthetic solution followed a logistic model on all the seed types

4 and did not follow the trend of test with digestate (Figure 5).

5

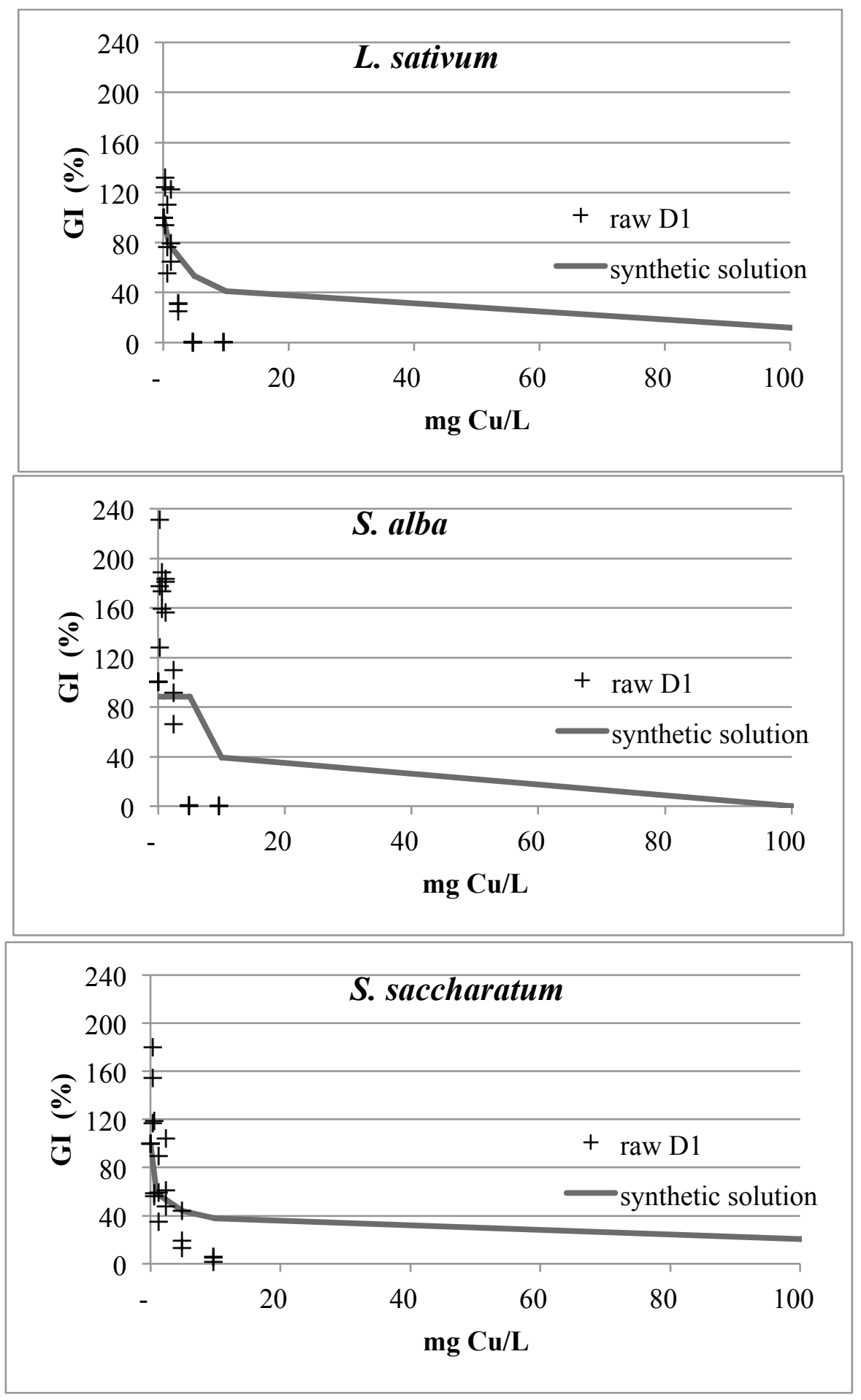

$9 \quad$ Figure 5 Effect of digestate D1 and synthetic solution of copper sulfate. 
1 The EC50 values were 5.9, 9.9 and $2.7 \mathrm{mg} \mathrm{Cu} / \mathrm{L}$ for L. sativum, S. alba and S. saccharatum, respectively. No bio-stimularion was detected with low concentration of $\mathrm{Cu}$ and it totally inhibited the germination at highest dose $(1,000 \mathrm{mg} \mathrm{Cu} / 1$ for L. sativum and $S$. saccharatum, $100 \mathrm{mg} / 1$ for $S$. alba). S. alba was the most sensitive specie to $\mathrm{Cu}$, in fact GI was near $0 \%$ at $100 \mathrm{mg} \mathrm{Cu} / \mathrm{L}$ while the index was $>10 \%$ for other species. Content of $\mathrm{Cu}$ comparable with digestate $(<10 \mathrm{mg} \mathrm{Cu} / \mathrm{L})$ did not affect the germination in a significant way; hence the metal was not the direct cause of digestate phytotoxicity.

\section{Conclusions}

The phytotoxicity of digestate from winery wastes was analyzed considering the germinated seeds percentage, root elongation and germination index in three macrophyte species. Results showed that effect on seed germination was not constant over time because of variability on substrates fed to the reactor. Low doses of digestate (3-5\%) stimulated the germination of $S$. alba and $S$. saccharatum and had no significant effect (difference to control lower than $20 \%$ ) on L. sativum. Higher doses reduced germination index until total inhibition with $50 \%$ of digestate. $S$. saccharatum appeared the less sensitive to this substrates, in fact the $40 \%$ of seed germinated also with raw digestate. Overall, the digestate did not meet the phytotoxicity criteria of Italian legislation (GI $>60 \%$ using solution of $30 \% \mathrm{v} / \mathrm{v}$ of digestate) that is a protective limit. In fact considering the limit of Nitrate Directive the maximum applicable digestate dose on soil should be of 4.1-3.3\%, corresponding to concentration range without significant inhibition.

Effect of ammonium and copper content were deeper investigated because they characterized this type of digestate. The macrophytes had EC50 of about $500 \mathrm{mgN} / \mathrm{L}$ exception for $S$. saccharatum (EC50 $37 \mathrm{mgN} / \mathrm{L}$ ), hence the concentration in the digestates (393-639 mg N/L) can't justify the observed inhibition. Neither $\mathrm{Cu}$ appeared as the main cause of inhibition, because test carried out with solution of ion $\mathrm{Cu}^{2+}$ totally inhibited germination at concentration higher than $100 \mathrm{mgCu} / \mathrm{L}$ while the digestate has content lower than $10 \mathrm{mg} \mathrm{Cu} / \mathrm{L}$. Direct correlation between ammonium/copper and phytotoxicity was not observed, probably there was a synergic effect of different compounds and metals in the digestate that is difficult to evaluate. 
2 The authors are grateful to Vinicola Serena srl for the valuable collaboration during this project and 3 for providing samples. We also wish to thank ATS scarl and the Treviso City Council for their 4 hospitality at Treviso Waste Water Treatment Plant. This research was supported by the University 5 Ca'Foscari of Venice IRIDE Project "Evaluation of digestate from anaerobic digestion of winery 6 waste in term of agronomic use". 


\section{References}

[1] S. Jain, S. Jain, I.T. Wolf, J. Lee, Y.W. Tong, A comprehensive review on operating parameters and different pretreatment methodologies for anaerobic digestion of municipal solid waste, Renew. Sustain. Energy Rev. 52 (2015) 142-154. doi:10.1016/j.rser.2015.07.091.

[2] L. Appels, J. Baeyens, J. Degrève, R. Dewil, Principles and potential of the anaerobic digestion of waste-activated sludge, Prog. Energy Combust. Sci. $34 \quad$ (2008) 755-781. doi:10.1016/j.pecs.2008.06.002.

[3] A.J. Ward, P.J. Hobbs, P.J. Holliman, D.L. Jones, Optimisation of the anaerobic digestion of $\begin{array}{llllll}\text { agricultural } & \text { resources, } & \text { Bioresour. } & \text { Technol. } & 99 & \text { (2008) }\end{array}$ doi:10.1016/j.biortech.2008.02.044.

[4] C. Da Ros, C. Cavinato, P. Pavan, D. Bolzonella, Mesophilic and thermophilic anaerobic co-digestion of winery wastewater sludge and wine lees: An integrated approach for sustainable wine production, J. Environ. Manage. (2016). doi:10.1016/j.jenvman.2016.03.029.

[5] J.A. Alburquerque, C. de la Fuente, A. Ferrer-Costa, L. Carrasco, J. Cegarra, M. Abad, M. P. Bernal, Assessment of the fertiliser potential of digestates from farm and agroindustrial residues, Biomass and Bioenergy. 40 (2012) 181-189. doi:10.1016/j.biombioe.2012.02.018.

[6] K. Lorenz, R. Lal, C.M. Preston, K.G.J. Nierop, Strengthening the soil organic carbon pool by increasing contributions from recalcitrant aliphatic bio(macro)molecules, Geoderma. 142 (2007) 110. doi:10.1016/j.geoderma.2007.07.013.

[7] J. Abubaker, K. Risberg, M. Pell, Biogas residues as fertilisers - Effects on wheat growth and soil microbial activities, Appl. Energy. 99 (2012) 126-134. doi:10.1016/j.apenergy.2012.04.050.

[8] M. Odlare, M. Pell, K. Svensson, Changes in soil chemical and microbiological properties during 4 years of application of various organic residues, Waste Manag. 28 (2008) 1246-1253. doi:10.1016/j.wasman.2007.06.005.

[9] A. Galvez, T. Sinicco, M.L. Cayuela, M.D. Mingorance, F. Fornasier, C. Mondini, Short term effects of bioenergy by-products on soil $\mathrm{C}$ and $\mathrm{N}$ dynamics, nutrient availability and biochemical properties, Agric. Ecosyst. Environ. 160 (2012) 3-14. doi:10.1016/j.agee.2011.06.015.

[10] K. Różyło, P. Oleszczuk, I. Jośko, P. Kraska, E. Kwiecińska-Poppe, S. Andruszczak, An ecotoxicological evaluation of soil fertilized with biogas residues or mining waste., Environ. Sci. Pollut. Res. Int. 22 (2015) 7833-42. doi:10.1007/s11356-014-3927-z.

[11] P. Alvarenga, P. Palma, A.P. Gonçalves, R.M. Fernandes, A.C. Cunha-Queda, E. Duarte, G. Vallini, Evaluation of chemical and ecotoxicological characteristics of biodegradable organic residues for 
application to agricultural land., Environ. Int. 33 (2007) 505-13. doi:10.1016/j.envint.2006.11.006.

[12] W. Wang, Literature review on higher plants for toxicity testing, Water, Air, Soil Pollut. 59 (1991) 381-400. doi:10.1007/bf00211845.

[13] D.P. Komilis, I.S. Tziouvaras, A statistical analysis to assess the maturity and stability of six composts, Waste Manag. 29 (2009) 1504-1513. doi:10.1016/j.wasman.2008.10.016.

[14] C. Teglia, A. Tremier, J.L. Martel, Characterization of solid digestates: Part 1, review of existing indicators to assess solid digestates agricultural use, Waste and Biomass Valorization. 2 (2011) 4358. doi:10.1007/s12649-010-9051-5.

[15] B.J. Young, P.F. Rizzo, N.I. Riera, V. Della Torre, V.A. López, C.D. Molina, F. E. Fernández, D. C. Crespo, R. Barrena, D. Komilis, A. Sánchez, Development of phytotoxicity indexes and their correlation with ecotoxicological, stability and physicochemical parameters during passive composting of poultry manure, Waste Manag. 54 (2016) 101-109. doi:10.1016/j.wasman.2016.05.001.

[16] F. Di Maria, A. Sordi, G. Cirulli, G. Gigliotti, L. Massaccesi, M. Cucina, Co-treatment of fruit and vegetable waste in sludge digesters. An analysis of the relationship among bio-methane generation, process stability and digestate phytotoxicity, Waste Manag. 34 (2014) 1603-1608. doi:10.1016/j.wasman.2014.05.017.

[17] A. Pivato, S. Vanin, R. Raga, M.C. Lavagnolo, A. Barausse, A. Rieple, A. Laurent, R. Cossu, Use of digestate from a decentralized on-farm biogas plant as fertilizer in soils: An ecotoxicological study for future indicators in risk and life cycle assessment., Waste Manag. 49 (2016) 378-89. doi:10.1016/j.wasman.2015.12.009.

[18] A Kapanen, M. Itävaara, Ecotoxicity tests for compost applications., Ecotoxicol. Environ. Saf. 49 (2001) 1-16. doi:10.1006/eesa.2000.1927.

[19] G. Gupta, P. Kelly, TOXICITY (EC50) COMPARISONS OF SOME ANIMAL WASTES, Water, Air Soil Pollut. 53 (1990) 113-117.

[20] N.F.Y. Tam, S. Tiquia, Assessing toxicity of spent pig litter using a seed germination technique, Resour. Conserv. Recycl. 11 (1994) 261-274. doi:10.1016/0921-3449(94)90094-9.

[21] K. Gell, J. van Groenigen, M.L. Cayuela, Residues of bioenergy production chains as soil amendments: Immediate and temporal phytotoxicity, J. Hazard. Mater. 186 (2011) 2017-2025. doi:10.1016/j.jhazmat.2010.12.105.

[22] K.L. McLachlan, C. Chong, R.P. Voroney, H.W. Liu, B.E. Holbein, Assessing the potential phytotoxicity of digestates during processing of municipal solid waste by anaerobic digestion: 
Comparison to aerobic composts, Acta Hortic. 638 (2004) 225-230.

[23] C. Teglia, A. Tremier, J.L. Martel, Characterization of solid digestates: Part 2, assessment of the quality and suitability for composting of six digested products, Waste and Biomass Valorization. 2 (2011) 113-126. doi:10.1007/s12649-010-9059-x.

[24] V. Tigini, M. Franchino, F. Bona, G.C. Varese, Is digestate safe? A study on its ecotoxicity and environmental risk on a pig manure., Sci. Total Environ. 551-552 (2016) 127-132. doi:10.1016/j.scitotenv.2016.02.004.

[25] M.H. Wong, Y.H. Cheung, C.L. Cheung, The effects of ammonia and ethylene oxide in animal manure and sewage sludge on the seed germination and root elongation of Brassica parachinensis, Environ. Pollut. Ser. A, Ecol. Biol. 30 (1983) 109-123. doi:10.1016/0143-1471(83)90008-9.

[26] J.L. Brenchley, R.J. Probert, Seed germination responses to some environmental factors in the seagrass Zostera capricorni from eastern Australia, Aquat. Bot. 62 (1998) 177-188. doi:10.1016/S0304-3770(98)00089-8.

[27] R. Boluda, L. Roca-Pérez, L. Marimón, Soil plate bioassay: An effective method to determine ecotoxicological risks, Chemosphere. 84 (2011) 1-8. doi:10.1016/j.chemosphere.2011.02.013.

[28] F. Tambone, B. Scaglia, G. D’Imporzano, A. Schievano, V. Orzi, S. Salati, F. Adani, Assessing amendment and fertilizing properties of digestates from anaerobic digestion through a comparative study with digested sludge and compost, Chemosphere. 81 (2010) 577-583. doi:10.1016/j.chemosphere.2010.08.034.

[29] C. Da Ros, C. Cavinato, F. Cecchi, D. Bolzonella, Anaerobic co-digestion of winery waste and waste activated sludge: Assessment of process feasibility, Water Sci. Technol. 69 (2014) 269-277. doi:10.2166/wst.2013.692.

[30] C. Da Ros, C. Cavinato, D. Bolzonella, P. Pavan, Renewable energy from thermophilic anaerobic digestion of winery residue: Preliminary evidence from batch and continuous lab-scale trials, Biomass and Bioenergy. 91 (2016) 150-159. doi:10.1016/j.biombioe.2016.05.017.

[31] T.I. Lafka, V. Sinanoglou, E.S. Lazos, On the extraction and antioxidant activity of phenolic compounds from winery wastes, Food Chem. $104 \quad$ (2007) 1206-1214. doi:10.1016/j.foodchem.2007.01.068.

[32] R. Baudo, B. Monica, B. Paola, R. Daria, Test di germinazione e allungamento radicale, Acqua \&Aria. (1999) 69-85.

[33] OECD, OECD Test Guideline 208: Terrestrial Plant Test - Seedling Emergence and Seedling Growth Test, Guidel. Test. Chem. Terr. Plant Test Seedl. Emerg. Seedl. Growth Test. 227 (2006) 1-21. 
doi:10.1787/9789264070066-en.

[34] R. Baudo, Report on the International Interlaboratory Comparison on the Phytotoxkit, (2012) 1-115.

[35] M. Beltrami, D. Rossi, R. Baudo, Phytotoxicity assessment of Lake Orta sediments, Aquat. Ecosyst. Health Manag. 2 (1999) 391-401. doi:10.1080/14634989908656977.

[36] A. Cesaro, V. Belgiorno, M. Guida, Compost from organic solid waste: Quality assessment and European regulations for its sustainable use, Resour. Conserv. Recycl. 94 (2015) 72-79. doi:10.1016/j.resconrec.2014.11.003.

[37] C. A. Schneider, W.S. Rasband, K.W. Eliceiri, NIH Image to ImageJ: 25 years of image analysis, Nat. Methods. 9 (2012) 671-675. doi:10.1038/nmeth.2089.

[38] P.H. Vanewijk, J.A. Hoekstra, Calculation of the EC50 and Its Confidence-Interval When Subtoxic Stimulus Is Present, Ecotoxicol. Environ. Saf. 25 (1993) 25-32. doi:10.1006/eesa.1993.1003.

[39] H. Saveyn, P. Eder, End-of-waste criteria for biodegradable waste subjected to biological treatment (compost \& digestate): Technical proposals, 2014. doi:10.2791/6295.

[40] A. Mekki, A. Dhouib, S. Sayadi, Polyphenols dynamics and phytotoxicity in a soil amended by olive mill wastewaters, J. Environ. Manage. 84 (2007) 134-140. doi:10.1016/j.jenvman.2006.05.015.

[41] C. Da Ros, C. Cavinato, P. Pavan, D. Bolzonella, Winery waste recycling through anaerobic codigestion with waste activated sludge., Waste Manag. 34 (2014) 2028-35. doi:10.1016/j.wasman.2014.07.017.

[42] G. Libralato, A. Costa Devoti, M. Zanella, E. Sabbioni, I. Mičetić, L. Manodori, A. Pigozzo, S. Manenti, F. Groppi, A. Volpi Ghirardini, Phytotoxicity of ionic, micro- and nano-sized iron in three plant species., Ecotoxicol. Environ. Saf. (2015). doi:10.1016/j.ecoenv.2015.07.024.

[43] H.-Y. Cui, Y. Zhao, Y.-N. Chen, X. Zhang, X.-Q. Wang, Q. Lu, L.M. Jia, Z.M. Wei, Assessment of phytotoxicity grade during composting based on EEM/PARAFAC combined with projection pursuit regression, J. Hazard. Mater. 326 (2017) 10-17. doi:10.1016/j.jhazmat.2016.09.059.

[44] G. Vallini, F. Cecchi, P. Pavan, A. Pera, J. Mata-Álvarez, A. Bassetti, RECOVERY AND DISPOSAL OF THE ORGANIC FRACTION OF MUNICIPAL SOLID WASTE (MSW) BY MEANS OF COMBINED ANAEROBIC AND AEROBIC BIO-TREATMENTS, 27 (1993) 121132. 